\title{
HEREDITARY SPASTIC PARAPLEGIA WITH AMYOTROPHY AND PES CAVUS
}

\author{
BY \\ HUGH G. GARLAND and C. E. ASTLEY \\ From the Department of Neurology, the General Infirmary at Leeds
}

\begin{abstract}
The hereditary " ataxias" comprise a group of well recognized degenerative disorders of the central nervous system wherein the neurological syndromes are largely determined by genetic transmission. Clinical evidence of involvement of the pyramidal tracts is often present, as for example in Friedreich's ataxia, but from a study of the literature it would seem that degeneration of the pryamidal tracts alone, producing a spastic paraplegia, occurs much less frequently. This is certainly the conclusion reached by Bell and Carmichael (1939) following their
\end{abstract} exhaustive study of the literature, and they considered hereditary spastic paraplegia to be extremely rare in Great Britain. It seems that Gee (1889) was the first to report such an occurrence here, describing three cases in one pedigree showing dominant inheritance ; Tooth (1891) published two pedigrees, each of two affected persons. The largest reported pedigree from this country however is that carefully described by Jones (1907). He observed a sibship of nine, eight boys and one girl; all the boys were affected to a greater or lesser extent but the girl was normal ; both parents were normal, there was no consanguinity, and no relatives were affected. Jones held that mutation might have occurred, but since the parents were normal and unrelated, no conclusion is drawn as to the mode of inheritance. Varying degrees of disability were noted amongst these patients, although the age of onset was uniform throughout (one to two years approximately). The cardinal signs were also present to an unequal though symmetrical extent in the different persons : they were confined to the legs, which were regarded as being thinner than was normal, usually with some degree of pes cavus. Most of the affected members showed a spastic gait together with an increase in muscle tone and tendon reflexes, the plantar responses being always extensor. There was no evidence of impaired sensation. The abdominal reflexes were present and equal in all cases. Jones writes that the power in the legs was never grossly diminished and that the disability, after a time, appeared to become almost stationary. It will be seen that these features are all present in the pedigree we shall describe.
Later, Ogilvie (1908) reported two affected persons in a family, but since that time there appear to be no further references from Great Britain. The largest number of cases of hereditary spastic paraplegia so far published from other countries are two pedigrees, both including 16 affected members, reported by Bayley (1897) and Bremer (1922), involving five and six generations respectively, with dominant inheritance. In both, the age of onset was in early childhood, probably under five years. In view of the apparent rarity of hereditary spastic paraplegia, we feel that the history of a family we saw recently should be recorded. We shall not describe each case in detail, so that following the account of Case II.6, the first person to be examined, it may be assumed that the remainder are similarly affected unless otherwise stated. All members in generations II and III have been examined by ourselves.

\section{Case Reports}

Case II.6.-A man, aged 31, stated that he had had difficulty in walking since the age of 11 , at which time he had been ill with a "fever" and on recovery noticed the disability for the first time. Since then his legs have always been stiff but, in his own view, there has been very little change in his condition for better or worse since a few months after the onset. He works as a mechanic, which involves standing for long periods. Apart from his weak legs he made no other complaint and there was no dysuria. The gait was spastic with some degree of crossing one leg in front of the other, but with no evident ataxia. He could just jump off the ground, though with difficulty. There was no evidence of mental deterioration and he was much concerned about the chances of any of his offspring eventually developing the disorder. There was no abnormality on examination of the cranial nerves or the arms; the latter were strong and showed normal muscular development. The abdominal reflexes were brisk and equal. Examination of the legs revealed a marked degree of diffuse wasting in all muscle groups below the knees. There was also well-marked pes cavus with callosities on the ball of each foot. Power in all movements, however, was surprisingly well maintained, although there was weakness of dorsiflexion at the ankle and of extension of the toes. Both legs were 
spastic, with very brisk tendon reflexes, and ankle clonus was present on both sides. The plantar responses were sharply extensor. There was no impairment on testing all forms of sensation.

Case II.1.-A housewife, aged 48, stated that she noticed stiffness in her legs developing at the age of eleven. She appeared to have rather more difficulty in walking than Case II.6, the legs again tending to cross in front of each other causing a " scissors gait." She was quite satisfied that there had been no deterioration in her condition for a number of years and she could do her housework and shopping with comparative ease.

The onset in Case III.1, was said to have followed an attack of diphtheria at the age of 12 , after which the patient walked stiffly; his gait was more cross-legged than his mother's (II.1) and he waddled a good deal, but he was a professional musician and could get about quite well. His unmarried sister, (III.2) aged 22, had the greatest disability in the group; her affection began at the age of 12 and although it was stationary she found walking an effort; however, she was also an asthmatic and had widespread eczema, so it seemed probable that psychogenic factors were playing a part in the incapacity. Case II.4, a man aged 38 , works as a clerk; he was normal until the age of 11 when it was first noticed that he wore out his boots unevenly. His son (III.10) aged 16, became affected at the age of 14 ; this was the mildest example of the series because the boy walked normally and could jump well off the ground with both feet together; early pes cavus was present but there was no muscular wasting below the knees. Case III.8, aged 17, developed the early signs when 12 years old; examination revealed all the constant features, and his mother (II.3) was unaffected. Case I.1, I.2, and I.3, are all dead, I.2 at the age of 71 from heart failure; he is said always to have walked slowly with a stiff gait and it seems highly probable that he was affected. Cases I.1 and I.2 were unrelated. The sister, (I.3) appears to have been affected, and here again the onset was at about 12 years of age. Thus there were in all nine affected members, seven of whom we have ourselves examined. We would emphasize that in no case was there any suggestion of mental deterioration, dysarthria, nystagmus, tremor, optic atrophy, fibrillation, ataxia, kypho-scoliosis, or vasomotor changes in the legs.

\section{Discussion}

This pedigree provides a clear example of spastic paraplegia inherited by dominant transmission. Case II.3 certainly possessed the gene and transmitted it to III.8, although she herself was unaffected and must be called a conductor. This anomaly is explained by the fact that skipping of a generation has occurred (Roberts, 1949a), a common event in the transmission of human dominant traits. The precise reason for this suppression is obscure but it has probably to do with the total effect produced by the interplay of all genes possessed by any given person ; in the case of II.3 these must have acted so as to cause the non-expression of the dominant gene she undoubtedly carried, thus preventing its effect. This example of skipping serves, therefore, to underline the fact that it is not possible to state that the unaffected child of an affected person cannot possess nor transmit the gene (Roberts, 1940). It also stresses the need to investigate as widely as possible amongst relatives when searching for possible genetic factors.

The age of onset of hereditary spastic paraplegia varies widely, more or less from birth to the fifth and sixth decades, although in the majority it is between the ages of three and fifteen years (Brain, 1947). It is remarkable how in many pedigrees the age of onset is fairly constant and in all of our cases was at or about the age of twelve. Many writers have drawn attention to some infectious illness having often just preceded the onset, but this happened in only two of our cases ; probably a period in bed merely makes a commencing disability the more obvious when walking is once again

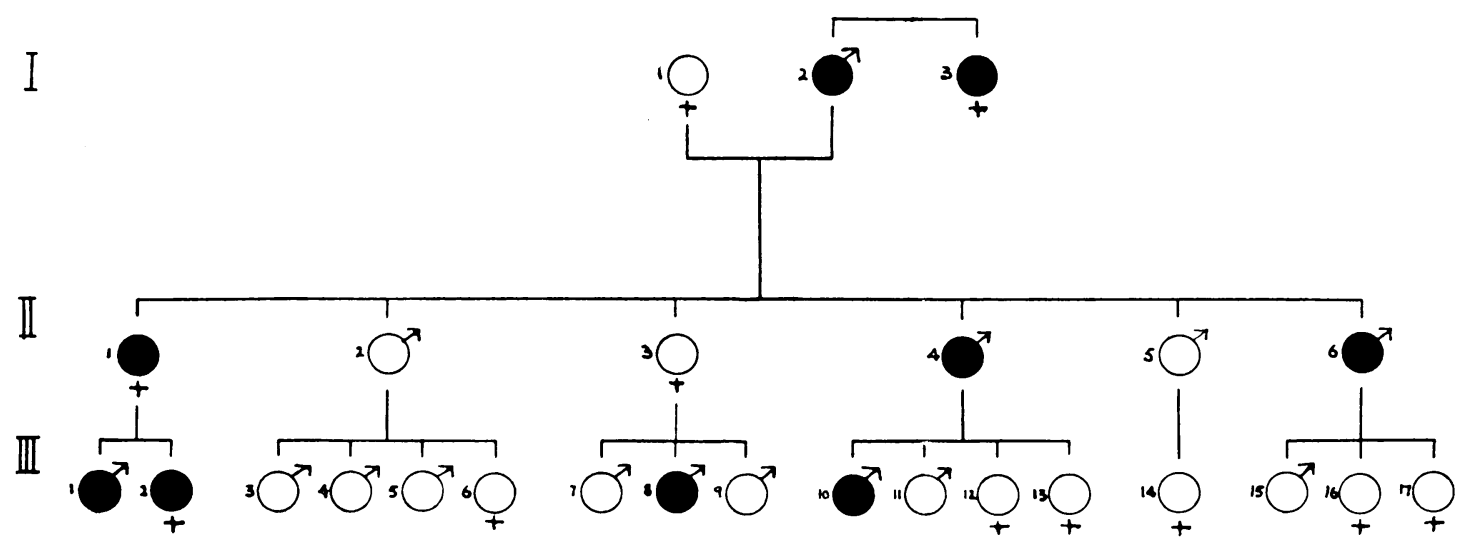

FIG. 1.-Pedigree of family described. 
resumed. The expectation of life is good and few die under 50 years of age (Bell and Carmichael, 1939) ; there is, of course, no reason why this disability should shorten life, bearing in mind that there are usually no sphincter disturbances and the patient rarely becomes bed-ridden. It is probable that Case I.2 lived 59 years with his paraplegia and Case II.1 enjoys perfect health 37 years after the onset of symptoms. We were impressed by the relatively minor amount of incapacity in our cases ; indeed all of them are living full lives.

Wasting of the leg muscles in association with hereditary spastic paraplegia appears to be extremely uncommon and has rarely been described. In our cases it was global and quite striking, such as might be seen, for instance, in peroneal muscular atrophy. We are unable to trace another pedigree quite like our own in this respect, with the possible exception of that reported by Jones (1907), although, occasionally, amyotrophy occurring in one or two affected persons within a pedigree has been reported, and particularly has this been so when the arms were similarly involved. In view of its severity we are disinclined to accept the suggestion that this wasting may be due to disuse, thus being purely a secondary effect of the paraplegia itself ; it is more likely that a lesion of the lower motor neurones is the true cause. Necropsies in these cases are very rare, but Eichhorst (1896) described atrophic anterior root fibres, whilst Pellizzi (1906) found degeneration in both anterior horn cells and root fibres. We have considered the possibility of a further explanation for this wasting. Instances of hereditary disorders of the central nervous system and peroneal muscular atrophy occurring within the same pedigree have been described (Biemond, 1928), and occasionally cases have been reported showing features of both, just as though each gene exerted its specific effect in the one person. In this pedigree, however, each person, excepting the youngest member, shows muscle wasting; there is no sign of this in any unaffected person in the family, and it is practically impossible that we could here be dealing with two genes (Roberts, 1949b). So far as the paraplegia alone is concerned, the absence of signs of involvement of the nervous system above the lower extremities suggests that the lesion of the pyramidal tracts is somewhere in the dorsal cord.

Pes cavus has been a constant finding in our cases and indeed it frequently occurs in the hereditary ataxias. The exact mode of production is not fully understood and many differing causes are usually cited which, if due to neurological disease, comprise spasticity in the legs or paralysis of the intrinsic muscles of the feet. Moreover, the onset of pes cavus from any cause shows the highest incidence at adolescence and thus it arises that, when neurogenic, its presence always suggests the possibility of a genetic origin. It seems therefore of interest to refer to a paper written by Collier (1899). He concluded that spasticity from any cause, provided it acted for a sufficient duration, tended to produce a greater or lesser degree of pes cavus, particularly in young people whose skeletal structures are less rigid than in later life ; this, he thought, could be produced by the increased tone existing in such conditions in the extensors of the toes, tibialis posticus, and peroneus longus. He noted that in all such instances the plantar responses were sharply extensor and drew the conclusion that the pattern of muscle tone producing pes cavus and the extensor response was identical. The youngest case in our series (III.10) showed no signs of wasting, but he had hypertonus, pes cavus, and sharply extensor plantar responses, suggesting that in this pedigree, at any rate, the pes cavus was unrelated to wasting in the feet and legs, thus supporting Collier's view. Nevertheless, bilateral pes cavus is also an almost constant feature of hereditary hypertrophic "neuritis" in which disease there is no lesion of the pyramidal tracts, so that spasticity is clearly not essential in its production.

Since there is a wide range in the age of onset of hereditary spastic paraplegia, it follows that the possibility of a genetic origin should be considered in all cases of spastic paraplegia of otherwise undetermined causation. Should there be a family history of others similarly affected the diagnosis becomes obvious, but there may be no such history particularly where the transmission is recessive and in families of small sibships, thus causing real difficulty in diagnosis. In such isolated instances the diagnosis would be suggested by the exclusion of other causes of spastic paraplegia, particularly early spinal compression and disseminated sclerosis. Routine investigation should rule out the former, but the error might still be made to attribute the isolated case in young adult life to the latter, and correct differentiation is important because the prognosis is clearly different. The frequent onset in childhood and the absence of remissions and disseminated physical signs serve to exclude disseminated sclerosis; moreover, the abdominal reflexes are almost constantly absent in this disease whereas they are often present in hereditary spastic paraplegia, whilst well developed pes cavus probably never occurs in disseminated sclerosis.

\section{Summary}

A family is described showing a syndrome of spastic paraplegia, amyotrophy, and pes cavus. It has been transmitted as a Mendelian dominant. The pes cavus is not produced by the amyotrophy. 
It is concluded that the amyotrophy is produced by the same gene which produces the spastic paraplegia and the pes cavus. Reference to the literature suggests that this is very rare and extremely so in Great Britain.

\section{REFERENCES}

Bayley, W. D. (1897). J. nerv. ment. Dis., 24, 697.

Bell, J., and Carmichael, E. A. (1939). "Treasury of Human Inheritance." London. 4, Part 3.

Biemond, A. (1928). Dtsch.Z. Nervenheilk., 104, 113.

Brain, W. R. (1947). " Diseases of the Nervous System." Oxford Medical Publications (London).
Bremer, F. W. (1922). Arch. Psychiat. Nervenkr., 66, 477.

Collier, J. S. (1899). Brain, 22, 71.

Eichhorst, H. (1896). Virchows Arch., 146, 173.

Gee, S. (1889). St. Barth. Hosp. Rep., 25, 81.

Jones, E. (1907). Rev. Neurol. Psychiat., 5, 98.

Ogilvie, G. (1908). Proc. R. Soc., Med. (Neurol. Sect.), 1,91.

Pellizzi, G. B. (1906). Riv. sper. Freniat., 32, 1.

Roberts, J. A. Fraser (1940). " An Introduction to Medical Genetics." Oxford Medical Publications (London).

(1949a). Personal communication.

(1949b). Personal communication.

Roth, M. (1948). Brain, 71, 416.

Tooth, H. H. (1891). St. Barth. Hosp. Rep., $27,7$.

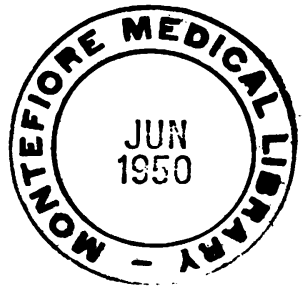

